\title{
Do N-arachidonyl-glycine (NA-glycine) and 2-arachidonoyl glycerol (2-AG) share mode of action and the binding site on the $\beta_{2}$ subunit of $\mathrm{GABA}_{A}$ receptors?
}

NA-glycine is an endogenous lipid molecule with analgesic properties, which is structurally

similar to the endocannabinoids 2-AG and anandamide but does not interact with

cannabinoid receptors. NA-glycine has been suggested to act at the G-protein coupled receptors GPR18 and GPR92. Recently, we have described that NA-glycine can also modulate recombinant $\alpha_{1} \beta_{2} \gamma_{2}$ GABA $_{A}$ receptors. Here we characterize in more detail this modulation and investigate the relationship of its binding site with that of the endocannabinoid 2-AG. 
1 Do N-arachidonyl-glycine (NA-glycine) and 2-arachidonoyl glycerol (2-AG) share mode of

2 action and the binding site on the $\beta_{2}$ subunit of $\mathrm{GABA}_{\mathrm{A}}$ receptors?

3 Roland Baur, Jürg Gertsch, Erwin Sigel

4 Institute of Biochemistry and Molecular Medicine, University of Bern, CH-3012 Bern,

5 Switzerland

6 Address correspondence to: Erwin Sigel, Institute of Biochemistry and Molecular Medicine,

7 University of Bern, Bühlstrasse 28, Ch-3012 Bern, Switzerland. Fax: +41 31631 3737, E-mail:

8 erwin.sigel@ibmm.unibe.ch

9 Abbreviations: GABA, $\gamma$-aminobutyric acid; $\mathrm{GABA}_{\mathrm{A}}$ receptor, $\gamma$-aminobutyric acid type A

10 receptor; NA-glycine: N-arachidonyl-glycine; 2-AG: 2-arachidonoyl glycerol; DEA,

11 docosatetraenylethanolamide. 


\section{Abstract}

13 NA-glycine is an endogenous lipid molecule with analgesic properties, which is structurally

14 similar to the endocannabinoids $2-\mathrm{AG}$ and anandamide but does not interact with cannabinoid 15 receptors. NA-glycine has been suggested to act at the G-protein coupled receptors GPR18 and

16 GPR92. Recently, we have described that NA-glycine can also modulate recombinant $\alpha_{1} \beta_{2} \gamma_{2}$

$17 \mathrm{GABA}_{\mathrm{A}}$ receptors. Here we characterize in more detail this modulation and investigate the 18 relationship of its binding site with that of the endocannabinoid 2-AG.

19 Keywords: $\mathrm{GABA}_{\mathrm{A}}$ receptors; GABA; endocannabinoids; 2-AG

20 Running title: The binding site for NA-glycine 
Introduction

22 GABA is the major inhibitory neurotransmitter in mammalian brain. Its fast effects are mediated

23 by synaptic and extrasynaptic $\mathrm{GABA}_{\mathrm{A}}$ receptors. These receptors are composed of five subunits

24 that surround a central chloride ion channel (Macdonald \& Olsen, 1994; Sieghart, 1995; Sieghart

$25 \&$ Sperk, 2002; Sigel \& Steinmann, 2012). The major receptor isoform consists of $\alpha_{1}, \beta_{2}$, and $\gamma_{2}$

26 subunits (Olsen \& Sieghart, 2008). Different approaches led to the widely accepted $2 \alpha: 2 \beta: 1 \gamma$

27 subunit stoichiometry (Chang et al., 1996; Tretter et al., 1997; Farrar et al., 1999; Baumann et al.,

28 2001, Baumann et al., 2002; Baur et al., 2006) with a subunit arrangement $\gamma \beta \alpha \beta \alpha$ anti-clockwise

29 as seen from the synaptic cleft (Baumann et al., 2001, Baumann et al., 2002; Baur et al., 2006).

30 The pharmacological properties are dependent on subunit composition (Sigel et al., 1990) and

31 arrangement (Minier and Sigel, 2004).

Neurosteroids (Belelli \& Lambert, 2005) and the endocannabinoid 2-AG (Sigel et al.,

33 2011) have been documented as endogenous ligands of $\mathrm{GABA}_{\mathrm{A}}$ receptors. A binding site for

34 2-AG has been shown to be present specifically on each of the two $\beta_{2}$ subunits present in a

35 pentameric receptor. Moreover it has been proposed that 2-AG dips into the membrane and binds

36 to the fourth trans-membrane sequence (M4) of $\beta_{2}$ subunits (Baur et al., 2013).

NA-glycine has been shown to be present in amounts of about $50 \mathrm{pmol} / \mathrm{g}$ dry weight in rat

38 brain tissue and about $140 \mathrm{pmol} / \mathrm{g}$ dry weight in spinal cord (Huang et al., 2001). This can be

39 compared to the levels of $2-\mathrm{AG}$ that have been reported to be 4 and $50 \mathrm{nmol} / \mathrm{g}$ wet weight in

40 brain (Sigel et al., 2011) and spinal cord (Guasti et al., 2009), respectively. Thus, NA-glycine is

41 about 1000-fold less abundant than 2-AG. NA-glycine has no functional affinity for $\mathrm{CB}_{1}$

42 receptors (Sheskin et al., 1997), but may activate the G protein coupled receptors GPR18 (Kohno

43 et al., 2006) and GPR92 (Oh et al., 2008) and target $\mathrm{Na}^{+} / \mathrm{Ca}^{2+}$-exchanger NCX (Bondarenko et al., 
44 2013) and T-type $\mathrm{Ca}^{2+}$-channels (Barbara et al., 2009). Interestingly, NA-glycine exerts analgesic

45 properties in different rodent models of pain (Huang et al., 2001; Succar, et al., 2007). Recently,

46 it has been reported that NA-glycine can also interact with glycine receptors, potentiating $\alpha_{1}$ and

47 interestingly inhibiting $\alpha_{2}$ and $\alpha_{3}$-containing glycine receptors (Yévenes \& Zeilhofer, 2011). It

48 should be noted that NA-glycine functionally interacts with glycine receptors with an apparent

49 affinity $>10 \mu \mathrm{M}$. This should be compared to the functional affinities to GABA $\mathrm{A}_{\mathrm{A}}$ receptors, NCX

50 and T-type $\mathrm{Ca}^{2+}$-channels that are estimated $<10 \mu \mathrm{M}$.

51 We have previously demonstrated that NA-glycine allosterically potentiates $\mathrm{GABA}_{\mathrm{A}}$

52 receptors (Baur et al., 2013), but it remained unclear whether this occurred via the same binding

53 site as 2-AG. The aim of the present study was therefore to establish whether NA-glycine acts at

54 the identical site on $\mathrm{GABA}_{\mathrm{A}}$ receptors as 2-AG. In most studied aspects Na-glycine acts similar to

55 2-AG, indicating a common binding site. However, some point mutations that abrogate

56 modulation by 2-AG leave the initial modulation by NA-glycine nearly unaffected and only over

57 time the modulation is gradually decreased to zero. Differential solubilization effects of 2-AG

58 and NA-glycine may account for this phenomena. Thus, at least during initial phases of

59 interaction with $\mathrm{GABA}_{\mathrm{A}}$ receptors the mode of binding is different for the two compounds.

60 Methods

61 Material

62 2-AG and NA-glycine were obtained from Cayman Chemical (Chemie Brunschwig,

63 Basel, Switzerland). All other chemicals, unless mentioned otherwise below, were from Sigma

64 (Buchs, Switzerland).

65 Expression of $\mathrm{GABA}_{\mathrm{A}}$ receptors in Xenopus oocytes 
67 plasmids with a cytomegalovirus promotor (pCMV vectors) containing the different subunits,

68 respectively. A poly-A tail of about 400 residues was added to each transcript using yeast poly-A 69 polymerase (United States Biologicals, Cleveland, OH, USA). The concentration of the cRNA 70 was quantified on a formaldehyde gel using Radiant Red stain (Bio-Rad Laboratories, Reinach,

71 Switzerland) for visualization of the RNA. Known concentrations of RNA ladder (Invitrogen, 72 Life Technologies, Zug, Switzerland) were loaded as standard on the same gel. cRNAs were 73 precipitated in ethanol/ isoamylalcohol $19: 1$, the dried pellet dissolved in water and stored at $74-80^{\circ} \mathrm{C}$. cRNA mixtures were prepared from these stock solutions and stored at $-80^{\circ} \mathrm{C}$. Xenopus 75 laevis oocytes were prepared, injected and defolliculated as described previously (Sigel, 1987; 76 Sigel \& Minier, 2005; Animal Permit No. BE98/12, Kantonaler Verterinärdienst, Kanton Bern). 77 They were injected with $50 \mathrm{~nL}$ of the cRNA solution containing rat wild type $\alpha_{1}$ and wild type or 78 mutated $\beta_{2}$ and wild type $\gamma_{2}$ subunits at a concentration of $10 \mathrm{nM}: 10 \mathrm{nM}: 50 \mathrm{nM}$ (Boileau et al., 79 2002) and then incubated in modified Barth's solution at $+18^{\circ} \mathrm{C}$ for at least $24 \mathrm{~h}$ before the 80 measurements. Where indicated concatenated subunits $\alpha_{1-}-\beta_{2}-\alpha_{1} / \gamma_{2}-\beta_{2}$ or $\alpha_{1}-\beta_{2}-\alpha_{1} / \gamma_{2}-\beta_{1}$ or $81 \alpha_{1}-\beta_{1}-\alpha_{1} / \gamma_{2}-\beta_{2}$ or $\alpha_{1}-\beta_{1}-\alpha_{1} / \gamma_{2}-\beta_{1}$ were used at a concentration of $25 \mathrm{nM}: 25 \mathrm{nM}$, each.

\section{Functional characterization of the $\mathrm{GABA}_{\mathrm{A}}$ receptors}

83 Currents were measured using a modified two-electrode voltage clamp amplifier Oocyte 84 clamp OC-725 (Warner Instruments, Camden, CT, USA) in combination with a XY-recorder 85 (90\% response time $0.1 \mathrm{~s}$ ) or digitized at $100 \mathrm{~Hz}$ using a PowerLab 2/20 (AD Instruments) using 86 the computer programs Chart (ADInstruments $\mathrm{GmbH}$, Spechbach, Germany). Tests with a model 87 oocyte were performed to ensure linearity in the larger current range. The response was linear up 88 to $15 \mu \mathrm{A}$. 
90 method at a holding potential of $-80 \mathrm{mV}$. The perfusion medium contained $90 \mathrm{mM} \mathrm{NaCl}, 1 \mathrm{mM}$

$91 \mathrm{KCl}, 1 \mathrm{mM} \mathrm{MgCl}, 1 \mathrm{mM} \mathrm{CaCl}, 5 \mathrm{mM}$ Na-HEPES (pH 7.4) and 0.5\% DMSO and was applied 92 by gravity flow $6 \mathrm{ml} / \mathrm{min}$. The perfusion medium was applied through a glass capillary with an 93 inner diameter of $1.35 \mathrm{~mm}$, the mouth of which was placed about $0.4 \mathrm{~mm}$ from the surface of the 94 oocyte. Allosteric modulation via the 2-AG site was measured at a GABA concentration eliciting 95 about $1 \%$ of the maximal GABA current amplitude $\left(\mathrm{EC}_{1}\right)$. In each experiment, $1 \mathrm{mM}$ GABA was 96 applied to determine the maximal current amplitude. Subsequently increasing concentrations of 97 GABA were applied until $0.5-1 \%$ of the maximal current amplitude was elicited $(0.3-3 \mu \mathrm{M})$. For 98 modulation experiments, GABA was applied for $20 \mathrm{~s}$ alone or in combination with 2-AG or 99 NA-glycine. 2-AG or NA-glycine were pre-applied for 30 s. Modulation of GABA currents was 100 expressed as $\left(\mathrm{I}_{(\text {modulator }+\mathrm{GABA})} / \mathrm{I}_{\mathrm{GABA}}-1\right) * 100 \%$. Inhibition by DEA was determined at the end of 101 a 1 min co-application with either NA-glycine or 2-AG following a $30 \mathrm{~s}$ pre-application of both 102 compounds. The perfusion system was cleaned between drug applications by washing with 103 dimethylsulfoxide to avoid contamination.

\section{Determination of critical micelle concentrations (CMC)}

Assays were performed as reported previously (Raduner et al., 2007). In brief, compounds

106 (from $2 \mathrm{mM}$ stock solutions) were incubated at increasing concentrations with $0.1 \mathrm{nM}$ fluorescein 107 (free acid, 99\%, Fluka, Switzerland) for $90 \mathrm{~min}$ at $30{ }^{\circ} \mathrm{C}$ in Nanopure distilled water. 108 Experiments were carried out on 96-well microtiter plates (excitation at $485 \mathrm{~nm}$, emission at 535 $109 \mathrm{~nm}$ ) on a TECAN Farcyte reader. Experiments were performed in triplicates in three independent 110 experiments and data are mean values \pm S.D. 


\section{Results}

112 Both NA-glycine and 2-AG allosterically potentiate recombinant $\alpha_{1} \beta_{2} \gamma_{2}$ GABA receptors

113 expressed in Xenopus oocytes. Both compounds share the arachidonoyl tail structure but differ in

114 their hydrophilic head groups (Fig. 1). Please note that at physiological pH, NA-glycine is

115 negatively charged. Here we wanted to compare the $\mathrm{GABA}_{\mathrm{A}}$ receptor binding site for NA-glycine

116 with the well-characterized binding site for 2-AG.

117 Figure 2a shows current traces of a cumulative concentration-response curve of the

118 allosteric potentiation of $\alpha_{1} \beta_{2} \gamma_{2} \mathrm{GABA}_{\mathrm{A}}$ receptors at a GABA concentration of $1 \mu \mathrm{M}$. At the

119 highest concentration used the current trace displayed the typical signs of an open channel block,

120 rapid apparent desensitization and an off current. This phenomenon made a precise curve fit

121 impossible as maximal potentiation could not be determined precisely. The averaged

122 concentration-response curve (Fig. 2b) was fitted with the assumption of different maximal

123 potentiation. From these fits it was estimated that the $\mathrm{EC}_{50}$ was between 1 and $10 \mu \mathrm{M}$ (not

124 shown $)$. Direct activation by $3 \mu \mathrm{M}$ NA-glycine elicited no significant current $(<2 \mathrm{nA})$ in oocytes

125 where $100 \mu \mathrm{M}$ GABA elicited a current $>7 \mu \mathrm{A}$.

126

Allosteric potentiation by $3 \mu \mathrm{M}$ NA-glycine was determined at different concentrations of

127 the endogenous agonist GABA. Fig. 3 shows that the degree of potentiation was rapidly

128 decreasing with increasing concentrations of GABA. The comparable properties of 2-AG are also

129 shown in Fig. 3. We tried to rationalize these findings using a model that has previously been

130 proposed on the basis of other observations (Baumann et al., 2003; Fig. 4a). This model assumes

131 binding of GABA to two sites differing in their binding affinity and transition to the open state

132 with low propensity of singly ligated states and high propensity of the doubly ligated state. Fig.

$1334 \mathrm{~b}$ shows computed current amplitudes in dependence of the GABA concentration. In addition, a 
134 predicted curve is shown where it is assumed that NA-glycine promotes transition of the singly

135 ligated receptor from the closed to the open state. Fig. 4c shows a computed GABA 136 concentration-dependence of the current potentiation expected in this case. The model predicts 137 that sizeable potentiation is limited to very low concentrations of GABA.

138 We have previously shown that the $\mathrm{CB}_{1}$ receptor ligand DEA antagonizes potentiation by 139 2-AG (Baur et al., 2013). Therefore, we compared the ability of DEA to antagonize potentiation 140 by NA-glycine and 2-AG. Based on the structural similarity of the three compounds we assumed 141 a competitive behaviour. Fig. 5 compares the cumulative concentration inhibition curves for 3 $142 \mu \mathrm{M}$ NA-glycine and for $3 \mu \mathrm{M}$ 2-AG. Potentiation by NA-glycine was inhibited half-maximally at $14372 \pm 36 \mu \mathrm{M}(\mathrm{n}=4)$ DEA and potentiation by $2-\mathrm{AG}$ at $1.4 \pm 0.6 \mu \mathrm{M}(\mathrm{n}=6)$. If the two ligands 144 displayed a similar apparent affinity for potentiation at the same site where DEA acts, providing 145 equal water solubility and lipid solubilization, a similar inhibitory potency of DEA would have 146 been expected. In order to investigate if DEA and NA-glycine act competitively, we repeated a 147 concentration inhibition curves at 6-times lower concentration $(0.5 \mu \mathrm{M})$ of NA-glycine.

148 Half-maximal inhibition was observed at $96 \pm 41 \mu \mathrm{M}(\mathrm{n}=4)$ DEA (Fig. 5). This could be 149 interpreted as non-competitive interaction of DEA with NA-glycine. Similarly, we performed 150 concentration inhibition curves at 1 and $15 \mu \mathrm{M}$ 2-AG. The higher concentration of 2-AG elicits 151 direct current that amount to less than $0.1 \%$ of the maximal current amplitude elicited by GABA 152 in the same oocytes. As expected for a competitive interaction between 2-AG and DEA, 153 half-maximal inhibition was shifted to the left upon decrease of the 2-AG concentration from 3 $154 \mu \mathrm{M}$ to $1 \mu \mathrm{M}$, but the inhibition curve became much flatter, indicating the DEA becomes partially 155 inactive at higher concentrations. Half-maximal inhibition for $15 \mu \mathrm{M}$ was not reached at 156 concentrations up to $100 \mu \mathrm{M}(\mathrm{n}=4)$ DEA (Fig. 5). In case of a non-competitive interaction of 
157 DEA with 2-AG an $\mathrm{IC}_{50}$ of about $1.4 \mu \mathrm{M}$ and in case of a competitive interaction an $\mathrm{IC}_{50}$ of about

$1587 \mu \mathrm{M}$ would be expected in the latter case. The observed results cannot be explained by classical 159 receptor theory and we therefore speculate that 2-AG and NA-glycine exhibit a different water

160 solubility and lipid solubilisation in the experimental setup. In the discussion we mention

161 possible explanations.

162 NA-glycine shows higher efficacy than 2-AG for potentiation of currents elicited by 163 GABA. 2-AG is metabolically stable in Xenopus oocytes as no degradation by serine hydrolases 164 was found (not shown). In case NA-glycine competes for the same binding site as 2-AG and both 165 molecules have a similar apparent affinity to this binding site, it would be anticipated that the 166 degree of potentiation by both agents at the same concentration would result in an intermediate 167 potentiation as compared to the individual agents. The apparent affinity of 2-AG has been 168 determined as $2 \mu \mathrm{M}$, while the apparent affinity of NA-glycine is estimated 1-10 $\mu \mathrm{M}$ here. As 169 shown in Fig. 6a, combined application results surprisingly in nearly the same extent of 170 potentiation as application of NA-glycine alone.

171 Again, this may be caused by a differential water solubility and membrane solubilisation 172 behaviour of NA-glycine and 2-AG. We therefore measured the critical micelle concentrations of 173 both molecules. The apparent $\mathrm{CMC}$ was $>100 \mu \mathrm{M}$ for NA-glycine and $4.2 \pm 0.5 \mu \mathrm{M}$ for $2-\mathrm{AG}$, 174 pointing to significant self-assembly and detergent behaviour of 2-AG.

As 2-AG fails to potentiate in $\mathrm{GABA}_{\mathrm{A}}$ receptors where the $\beta_{2}$ subunit is replaced by $\beta_{1}$,

176 we tested potentiation by NA-glycine in $\alpha_{1} \beta_{1} \gamma_{2}$ receptors (Fig. 6b). Similarly to 2-AG, 177 potentiation by NA-glycine depends on the presence of $\beta_{2}$ subunits. We studied potentiation by 178 NA-glycine in concatenated receptors containing either two $\beta_{2}$ subunits, two $\beta_{1}$ subunits or one 179 each $\beta_{1}$ and $\beta_{2}$ in different positions in the receptor pentamer (Fig. 7). Receptors containing two 
181 weak potentiation. Intermediate potentiation was observed in receptors containing one each, $\beta_{1}$

182 and $\beta_{2}$. This strongly indicates that the NA-glycine binding site is located on the $\beta_{2}$ subunit as

183 previously shown with 2-AG (Sigel et al., 2011).

184 A number of point mutations have been described to interfere with the potentiation by

185 2-AG. We tested the effect of the point mutations $\beta_{2} \mathrm{~W} 428 \mathrm{C}, \beta_{2} \mathrm{~S} 429 \mathrm{C}, \beta_{2} \mathrm{~F} 432 \mathrm{C}, \beta_{2} \mathrm{~F} 439 \mathrm{~L}$ and

$186 \beta_{2} \mathrm{~V} 443 \mathrm{C}$. Original current traces are shown for the mutant receptor $\alpha_{1} \beta_{2} \mathrm{~S} 429 \mathrm{C} \gamma_{2}$. These traces

187 are compared with traces from wild type receptors (Fig. 8a). While wild type receptors show a

188 time-independent potentiation by NA-glycine, mutant receptors showed initially a potentiation

189 that rapidly decayed over time. As these mutant receptors show a similar dependence on GABA

190 as wild type receptors, and the experiment were carried out at very low GABA concentrations

191 this current transient is not due to desensitization. In the case of 2-AG the effect of these

192 mutations is a reduction of the potentiation independent of the time of exposure to 2-AG. This

193 behaviour is observed with NA-glycine for the potentiation of $\alpha_{1} \beta_{2} \mathrm{~F} 432 \mathrm{C} \gamma_{2}$ receptors, but not the

194 other mutant receptors studied.

195 The mutation studies indicate a site of action in the inner leaflet of M4 of the $\beta_{2}$ subunit.

196 In this case NA-glycine has to traverse the lipid bilayer either by diffusion or mediated by a

197 transport system and this may require some time. In order to test the time-dependence of action of

198 NA-glycine we exposed an oocyte to GABA followed by GABA and NA-glycine (Fig. 9).

199 Indeed, onset of modulation was slow and did not reach a steady level within 1 min. Upon switch

200 of the medium to GABA only, a slow decay of the potentiation was observed.

\section{Discussion}


203 2-AG. We aimed at localizing the site of interaction of Na-glycine with recombinant $\alpha_{1} \beta_{2} \gamma_{2}$

$204 \mathrm{GABA}_{\mathrm{A}}$ receptors relative to the site for 2-AG. An interpretation of our results is hampered by

205 the fact that the apparent affinity for the potentiation by NA-glycine could not be determined

206 accurately. However, we can estimate this value to be in the range of 1-10 $\mu \mathrm{M}$, which compares

207 well with the value of $2 \mu \mathrm{M}$ for $2-\mathrm{AG}$ (Sigel et al., 2011). The fact that we find significant

208 potentiation of $\mathrm{GABA}_{\mathrm{A}}$ receptors by $>0.1 \mu \mathrm{M}$ NA-glycine may reflect the better water solubility

209 of NA-glycine over 2-AG at low concentrations and even indicate biological relevance as the

210 average in vivo concentration in the central nervous system may be estimated from the dry tissue

211 content as about 15-50 $\mathrm{nM}$ and NA-glycine is unlikely to be randomly distributed.

212 The following observations argue for a similar mode of action of NA-glycine and 2-AG.

213 First, both substances only act exclusively at low GABA concentration (Fig. 3), putatively by

214 enhancing the opening of singly ligated receptor channels (Fig. 4). A leftward shift of the

215 concentration response curve for GABA as observed in the case of benzodiazepines does not

216 abrogate potentiation below $\mathrm{EC}_{50}$ (Sigel and Steinmann, 2012). To our knowledge, this is a new

217 mode of action of a ligand. Second, investigation of receptors with different $\beta$ subunits (Fig. 5)

218 and experiments with concatenated receptors containing either no, one, or two $\beta_{2}$ subunits (Fig.

219 6) strongly indicate that both ligand binding sites are located on the $\beta_{2}$ subunit. A common

220 binding site in the inner leaflet of the fourth trans-membrane region (M4) of this subunit is

221 suggested by the fact that modulation by both agents is either reduced or abolished in five

222 identical mutant receptors, at least in the late phase of action of NA-glycine (Fig. 8b). The onset

223 of action for both substances was found to be slow (Fig. 9; Baur et al., 2013). On the basis of

224 these observations, it is tempting to assume a common binding site for the two ligands. 
226 NA-glycine and 2-AG use an identical binding site, i.e. display a similar apparent affinity and 227 interact with each other in a competitive way. Combined application of two compounds with 228 similar affinities at identical concentrations is then expected to result in an intermediate 229 potentiation as compared to that by individual compounds. Instead, the observed potentiation is 230 similar to the one by NA-glycine alone. A second observation is difficult to reconcile with a 231 common binding site for NA-glycine, 2-AG and the inhibitor of the potentiation of 2-AG, DEA. 232 Namely, DEA prevents potentiation by NA-glycine only at 50-fold higher concentrations as that 233 caused by 2-AG. As mentioned in the result section, the interaction between DEA and 2-AG 234 cannot be explained by classical receptor theory. Since NA-glycine exerts a significant higher 235 CMC than 2-AG, differential solubilisation of NA-glycine and 2-AG with Xenopus oocytes may 236 account for some of the effects observed in this study. The way these lipids are organized in an 237 aqueous environment will affect entry of the molecules into the bilayer, binding equilibrium, and 238 the way the receptor is occupied. If this holds true the observations with co-application of 239 NA-glycine and 2-AG as well as the inhibition of NA-glycine and DEA have to be seen in a new 240 light. In spite of our observations the three agents could still all bind to largely overlapping sites 241 within an extended surface able to bind flexible hydrophobic structures. The mutant receptors $\alpha_{1} \beta_{2} \mathrm{~S} 428 \mathrm{C} \gamma_{2}, \alpha_{1} \beta_{2} \mathrm{R} 429 \mathrm{C} \gamma_{2}, \alpha_{1} \beta_{2} \mathrm{~F} 439 \mathrm{~L} \gamma_{2}$ and $\alpha_{1} \beta_{2} \mathrm{Y} 443 \mathrm{C} \gamma_{2}$ all

243 largely abrogate modulation by NA-glycine after 1 min of combined application of GABA with 244 NA-glycine. This abrogation is not present at the beginning of the combined application, but sets 245 in rather slowly. We have no explanation for this observation. Solubility considerations do not 246 help to explain this phenomenon. 
248 for NA-glycine and 2-AG. No matter what the exact mode of interaction of NA-glycine with the

$249 \mathrm{GABA}_{\mathrm{A}}$ receptor is, this agent represents by far the stronger positive allosteric modulator than

250 2-AG, although the latter is more abundant in brain. The implications of our findings for the 251 analgesic effect of NA-glycine remain to be studied.

\section{Acknowledgments}

253 We thank Dr. V. Niggli for carefully reading the manuscript and Dr. A. Chicca for determining 254 stability of 2-AG in Xenopus oocytes.

\section{References}

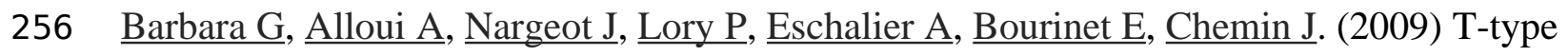
257 calcium channel inhibition underlies the analgesic effects of the endogenous lipoamino $258 \quad$ acids. Journal of Neuroscience 29:13106-13114.

259 Baumann SW, Baur R, Sigel E. 2001. Subunit arrangement of gamma-aminobutyric acid type A 260 receptors. Journal of Biological Chemistry 276:36275-36280.

261 Baumann SW, Baur R, Sigel E. 2002. Forced subunit assembly in $\alpha_{1} \beta_{2} \gamma_{2} \mathrm{GABA}_{\mathrm{A}}$ receptors. 262 Insight into the absolute arrangement. Journal of Biological Chemistry 277:46020-46025. 263 Baumann SW, Baur R, Sigel E. 2003. Individual properties of the two functional agonist sites in

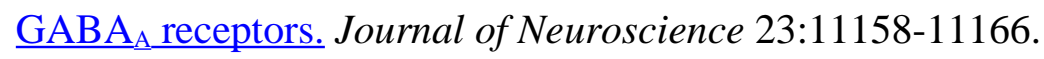


265 Baur R, Kielar M, Richter L, Ernst M, GF Ecker, Sigel E. 2013 Molecular analysis of the site for

266 2-arachidonylglycerol (2-AG) on the $\beta_{2}$ subunit of GABA $\mathrm{A}_{\mathrm{A}}$ receptors. Journal of

$267 \quad$ Neurochemisty, in press, doi: 10.1111/jnc.12270.

268 Baur R, Minier F, Sigel E. 2006. A GABA A $_{\mathrm{A}}$ receptor of defined subunit composition and 269 positioning: concatenation of five subunits. FEBS Letters 580:1616-1620.

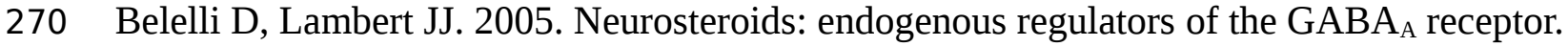
$271 \quad$ Nature Reviews in Neuroscience 6:565-575.

272 Boileau AJ, Baur R, Sharkey LM, Sigel E, Czajkowski C. 2002. The relative amount of cRNA 273 coding for $\gamma 2$ subunits affects stimulation by benzodiazepines in $\mathrm{GABA}_{\mathrm{A}}$ receptors 274 expressed in Xenopus oocytes. Neuropharmacology 43:695-700.

275 Bondarenko AI, Drachuk K, Panasiuk O, Sagach V, Deak AT, Malli R, Graier WF. (2013) $276 \underline{\mathrm{N} \text {-arachidonoyl glycine suppresses } \mathrm{Na}^{+} / \mathrm{Ca}^{2+} \text { exchanger-mediated } \mathrm{Ca}^{2+} \text { entry into }}$ 277 endothelial cells and activates BKCa channels independently of GPCRs. British Journal of Pharmacology 169:933-948.

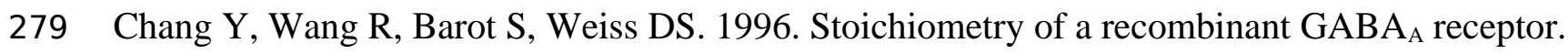
$280 \quad$ Journal of Neuroscience 16:5415-5424.

281 Guasti L, Richardson D, Jhaveri M, Eldeeb K, David Barrett D, Elphick MR, Alexander SPH, 282 Kendall D, Michael GJ, Chapman V (2009) Minocycline treatment inhibits microglial activation and alters spinal levels of endocannabinoids in a rat model of neuropathic pain. Molecular Pain 5:35-45.

285 Farrar SJ, Whiting PJ, Bonnert TP, McKernan RM. 1999. Stoichiometry of a ligand gated ion 286 channel determined by fluorescence energy transfer. Journal of Biological Chemistry 287 274:10100-10104. 
288 Huang SM, Bisogno T, Petros TJ, Chang SY, Zavitsanos PA, Zipkin RE, Sivakumar R, Coop A, 289 Maeda DY, De Petrocellis L, Burstein S, Di Marzo V, Walker JM. 2001. Identification of 290 a new class of molecules, the arachidonyl amino acids, and characterization of one

291 member that inhibits pain. Journal of Biological Chemistry 276:42639-42644.

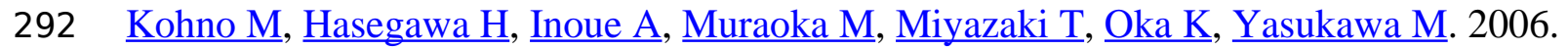

293 Identification of N-arachidonylglycine as the endogenous ligand for orphan 294 G-protein-coupled receptor GPR18. Biochemical and Biophysical Research $295 \quad$ Communications 347:827-832.

296 Macdonald RL, Olsen RW. 1994. GABA A receptor channels. Annual Reviews in Neuroscience $297 \quad 17: 569-602$.

298 Minier F, Sigel E. 2004. Positioning of the - subunit isoforms confers a functional signature to 299 300 $\gamma$-aminobutyric acid type A receptors. Proceedings of the National Academy of Sciences of the United States of America 101:7769-7774.

Oh DY, Yoon JM, Moon MJ, Hwang JI, Choe H, Lee JY, Kim JI, Kim S, Rhim H, O'Dell DK, Walker JM, Na HS, Lee MG, Kwon HB, Kim K, Seong JY. (2008) Identification of farnesyl pyrophosphate and $\mathrm{N}$-arachidonylglycine as endogenous ligands for GPR92.

Olsen RW, Sieghart W. 2008. International Union of Pharmacology. LXX. Subtypes of gamma-aminobutyric acid(A) receptors: classification on the basis of subunit composition, pharmacology, and function. Update. Pharmacological Reviews 60:243-60.

308 Raduner, S Bisson W, Abagyan R, Altmann KH, Gertsch J. 2007. Self-assembling 309 cannabinomimetics: supramolecular structures of N-alkyl amides. J Nat Prod. 70:1010-1015. 
311 Sheskin T, Hanus L, Slager J, Vogel Z, Mechoulam R. 1997. Structural requirements for binding

312 of anandamide-type compounds to the brain cannabinoid receptor. Journal of Medicinal

313 Chemistry 40:659-667.

314 Sieghart W. 1995. Structure and pharmacology of gamma-aminobutyric acidA receptor subtypes.

$315 \quad$ Pharmacological Reviews 47:181-233.

316 Sieghart W, Sperk G. 2002. Subunit composition, distribution and function of GABA receptor

317 subtypes. Current Topics Medicinal Chemistry 2:795-816.

318 Sigel E. 1987. Properties of single sodium channels translated by Xenopus oocytes after

319 injection with messenger ribonucleic acid. Journal of Physiology 386:73-90.

320 Sigel E, Minier F. 2005. The Xenopus oocyte: system for the study of functional expression and 321 modulation of proteins. Molecular Nutrition and Food Research 49:228-234.

322 Sigel E, Baur R, Trube G, Mohler H, Malherbe P. 1990. The effect of subunit combination of rat brain $\mathrm{GABA}_{\mathrm{A}}$ receptors on channel function. Neuron 5:703-711.

324 Sigel E, Baur R, Rácz I, Marazzi J, Smart TG, Zimmer A, Gertsch J. 2011. The major central 325 endocannabinoid directly acts at $\mathrm{GABA}_{\mathrm{A}}$ receptors. Proceedings of the National Academy 326 of Sciences of the United States of America 108:18150-18155.

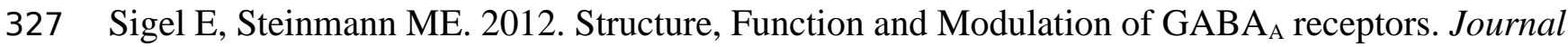
$328 \quad$ of Biological Chemistry 287:40224-40231.

329 Succar R, Mitchell VA, Vaughan CW. 2007. Actions of N-arachidonyl-glycine in a rat 330 inflammatory pain model. Molecular Pain 3:24.

331 Tretter V, Ehya N, Fuchs K, Sieghart W. 1997. Stoichiometry and assembly of a recombinant 332 $\mathrm{GABA}_{\mathrm{A}}$ receptor subtype. Journal of Neuroscience 17:2728-2737.

333 Yevenes GE, Zeilhofer HU. 2011. Molecular sites for the positive allosteric modulation of 
337 Figure 1 Chemical structure of NA-glycine and 2-AG.

338 Figure 2 Concentration-dependent potentiation of currents mediated by recombinant

$339 \boldsymbol{\alpha}_{1} \boldsymbol{\beta}_{2} \boldsymbol{\gamma}_{\mathbf{2}} \mathbf{G A B \mathbf { A } _ { \mathbf { A } }}$ receptors. a) Receptors were expressed in Xenopus oocytes and currents were 340 measured by using electrophysiological techniques at a GABA concentration eliciting 0.5-1.0\% 341 of the maximal current amplitude $\left(\mathrm{EC}_{0.5-1.0}\right)$. GABA was applied twice (single bars) and 342 subsequently in combination with increasing concentrations of NA-glycine. The numbers above 343 the double bars indicate the concentration of NA-glycine in $\mu \mathrm{M}$. NA-glycine was pre-applied for $34430 \mathrm{~s}$. Original current traces are shown. b) shows the averaged concentration-dependent 345 potentiation of currents elicited by GABA by NA-glycine. Four experiments as shown 346 under a) were averaged. Data are shown as mean \pm SD $(n=4)$. Such an 347 averaged curve has been shown before based on 3 experiments and missing the point at $10 \mu \mathrm{M}$ 348 NA-glycine (Baur et al., 2013).

349 Figure 3 Influence of the GABA concentration. Current potentiation by $3 \mu \mathrm{M}$

350 NA-glycine (closed circles) or 2-AG (closed squares) was determined at different concentrations 351 of GABA. Potentiation decreased with increasing concentrations of GABA. The GABA 352 concentration response curve was fitted with a mean $\mathrm{EC}_{50}$ of $35 \mu \mathrm{M}$ and a mean Hill coefficient 353 of 1.5 (not shown).

354 Figure 4 Mode of action of NA-glycine. Simplified model a) The model assumes two 355 agonist binding sites 1 and 2 with different affinities. 2-AG affects the closed / open transition of 
356 the two singly ligated states. The receptor R can first bind GABA (A) either to the site 1 (AR) or

357 the site 2 (RA). The receptor occupied by two agonist molecules ARA can isomerize to the open

358 state $\mathrm{ARA}^{*}$, the receptors occupied by a single agonist molecule can isomerize to the open states

359 AR* and RA*. Binding is described with $\mathrm{K}$ as dissociation constants and gating with $\mathrm{L}$ as closed

360 state / open state equlibrium. c) Theoretical GABA concentration response curves in the absence

361 and presence of NA-glycine. The following parameters were assumed: 0.24 for L, 10 and 2.2 for

$362 \mathrm{~L}_{1}$ in the absence and presence of NA-glycine, respectively, 11 and 2.4 for $\mathrm{L}_{2}$ in the absence

363 (line) and presence (dashed line) of NA-glycine, respectively, $30 \mu \mathrm{M}$ for $\mathrm{K}_{1}, 90 \mu \mathrm{M}$ for $\mathrm{K}_{2}$. c)

364 Dependence of the potentiation by NA-glycine on the concentration of GABA obtained by the

365 ratio of the computed current in the presence of NA-glycine divided by the current in its absence.

366 Figure 5 Concentration inhibition curve of DEA. Increasing concentrations of DEA were

367 co-applied with $1 \mu \mathrm{M}$ 2-AG (open circles), $3 \mu \mathrm{M}$ 2-AG (open squares), $15 \mu \mathrm{M} 2-\mathrm{AG}$ (open

368 diamonds), $0.5 \mu \mathrm{M}$ NA-glycine (filled circles), or $3 \mu \mathrm{M}$ NA-glycine (filled squares). Data are

369 shown as mean $\pm \operatorname{SEM}(n=4)$.

370

Figure 6 Effect of subunit combination and co-application with 2-AG. a) Current

371 potentiation by the combined application of $3 \mu \mathrm{M}$ NA-glycine and $3 \mu \mathrm{M} 2-\mathrm{AG}$ is compared with

372 the individual application of the two substances. b) Current potentiation by $3 \mu \mathrm{M}$ NA-glycine in

$373 \alpha_{1} \beta_{2} \gamma_{2}$ receptors and $\alpha_{1} \beta_{1} \gamma_{2}$ receptors. Potentiation is strongly dependent on the presence of the $\beta_{2}$

374 subunit.

375 Figure 7 Concentration-dependent potentiation of currents mediated by concatenated 
$376 \mathbf{G A B A}_{\mathbf{A}}$ receptors. Concatenated $\alpha_{1}-\beta_{1}-\alpha_{1} / \gamma_{2}-\beta_{1}, \alpha_{1}-\beta_{1}-\alpha_{1} / \gamma_{2}-\beta_{2}, \alpha_{1}-\beta_{2}-\alpha_{1} / \gamma_{2}-\beta_{1}$ or

$377 \alpha_{1}-\beta_{2}-\alpha_{1} / \gamma_{2}-\beta_{2}$ receptors were expressed in Xenopus oocytes and currents were measured at a 378 GABA concentration eliciting 0.5-1.0\% of the maximal current amplitude $\left(\mathrm{EC}_{0.5-1.0}\right)$. Current

379 potentiation by increasing concentrations of NA-glycine was determined. Four such experiments 380 were averaged. Data are shown as mean $\pm \operatorname{SD}(n=4)$.

\section{Figure 8 Effect of point mutations that reduced potentiation by 2-AG on the}

382 potentiation of NA-glycine. a) Potentiation by $3 \mu \mathrm{M}$ NA-glycine is compared between wild type 383 receptors and receptors containing the point mutation $\mathrm{S} 429 \mathrm{C}$ in the $\beta_{2}$ subunit. This mutation 384 results at the beginning of the drug application in an about $50 \%$ reduction of potentiation and 385 after 1 min drug application potentiation is abolished. b) Wild type receptors are compared with 386 mutant receptors. Current potentiation is indicated at the beginning of the drug application (filled 387 bars) and after 1 min drug exposure (open bars).

388 Figure 9 Time course of the potentiation by NA-glycine. An oocyte expressing $\alpha_{1} \beta_{2} \gamma_{2}$ 389 receptors was sequentially exposed to medium alone, to $1 \mu \mathrm{M}$ GABA, to the same concentration 390 of GABA in combination with $5 \mu \mathrm{M}$ NA-glycine, to $1 \mu \mathrm{M}$ GABA alone and the to medium. This 391 experiment was repeated two more times with similar results. 


\section{Figure 1}

Chemical structure of NA-glycine and 2-AG 

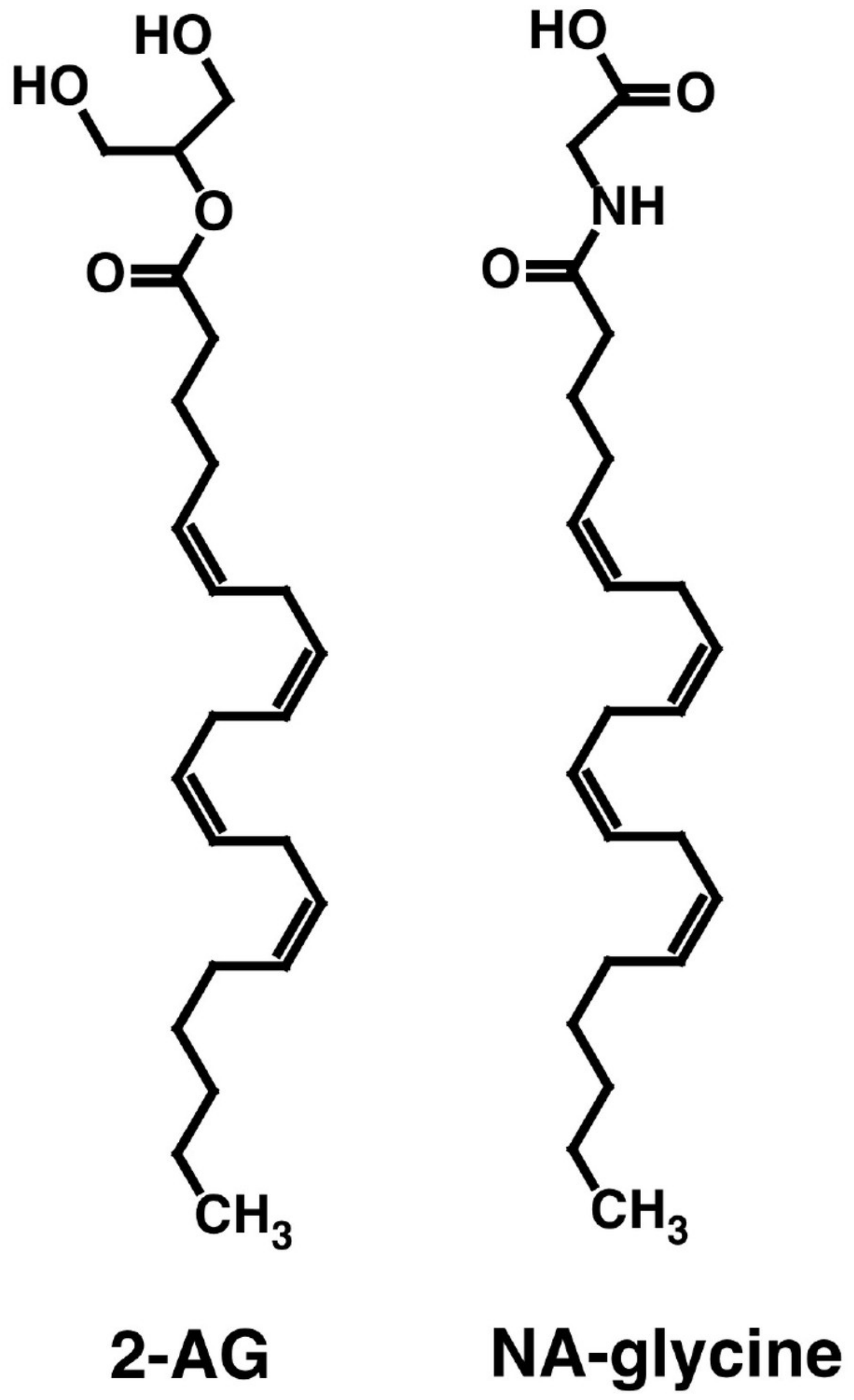


\section{Figure 2}

Concentration-dependent potentiation of currents mediated by recombinant $\alpha_{1} \beta_{2} \gamma_{2}$ $\mathrm{GABA}_{\mathrm{A}}$ receptors

a) Receptors were expressed in Xenopus oocytes and currents were measured by using electrophysiological techniques at a GABA concentration eliciting $0.5-1.0 \%$ of the maximal current amplitude $\left(\mathrm{EC}_{0.5-1.0}\right)$. Original current traces are shown. The experiment was carried out with a GABA concentration of $1 \mathrm{M}$. b) Four such experiments were averaged. Data are shown as mean $\pm S D(n=4)$. 


\section{Figure 3}

Influence of the GABA concentration

Current potentiation by 3 micro M NA-glycine (closed circles) or 2-AG (closed squares) was determined at different concentrations of GABA. Potentiation decreased with increasing concentrations of GABA.

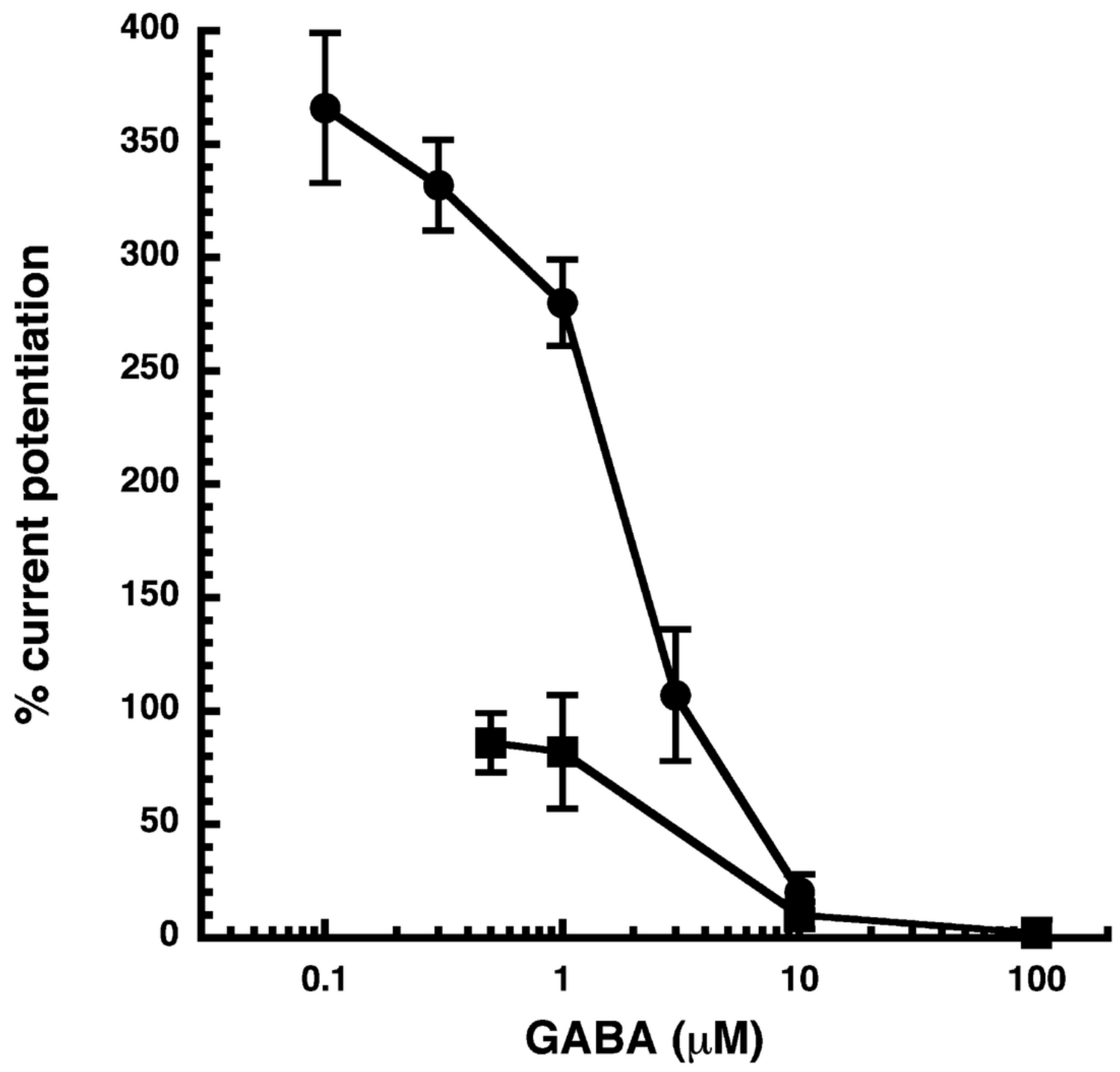




\section{Figure 4}

Mode of action of NA-glycine

Simplified model a) The model assumes two agonist binding sites 1 and 2 with different affinities. 2-AG affects the closed / open transition of the two singly ligated states. The receptor $\mathrm{R}$ can first bind GABA (A) either to the site $1(A R)$ or the site $2(R A)$. The receptor occupied by two agonist molecules ARA can isomerize to the open state ARA*, the receptors occupied by a single agonist molecule can isomerize to the open states $\mathrm{AR}^{*}$ and $\mathrm{RA}^{*}$. Constants are taken as dissociation constants and gating constants as closed state / open state. c) Theoretical GABA concentration response curves in the absence and presence of NA-glycine. The following parameters were assumed: 0.24 for $L, 10$ and 2.2 for $L_{1}$ in the absence and presence of NA-glycine, respectively, 11 and 2.4 for $L_{2}$ in the absence (line) and presence (dashed line) of NA-glycine, respectively, $30 \mu \mathrm{M}$ for $\mathrm{K}_{1}, 90 \mu \mathrm{M}$ for $\mathrm{K}_{2}$. c) Dependence of the potentiation by NA-glycine on the concentration of GABA obtained by the ratio of the computed current in the presence of NA-glycine divided by the current in its absence. 
a

$A R \rightleftharpoons A R^{*}$

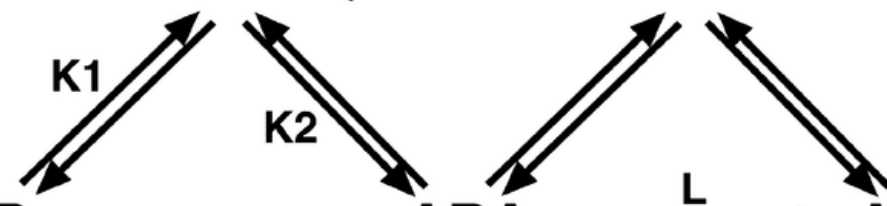

R

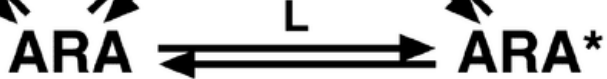

1

$\mathrm{K} 2$

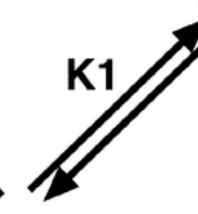

RA

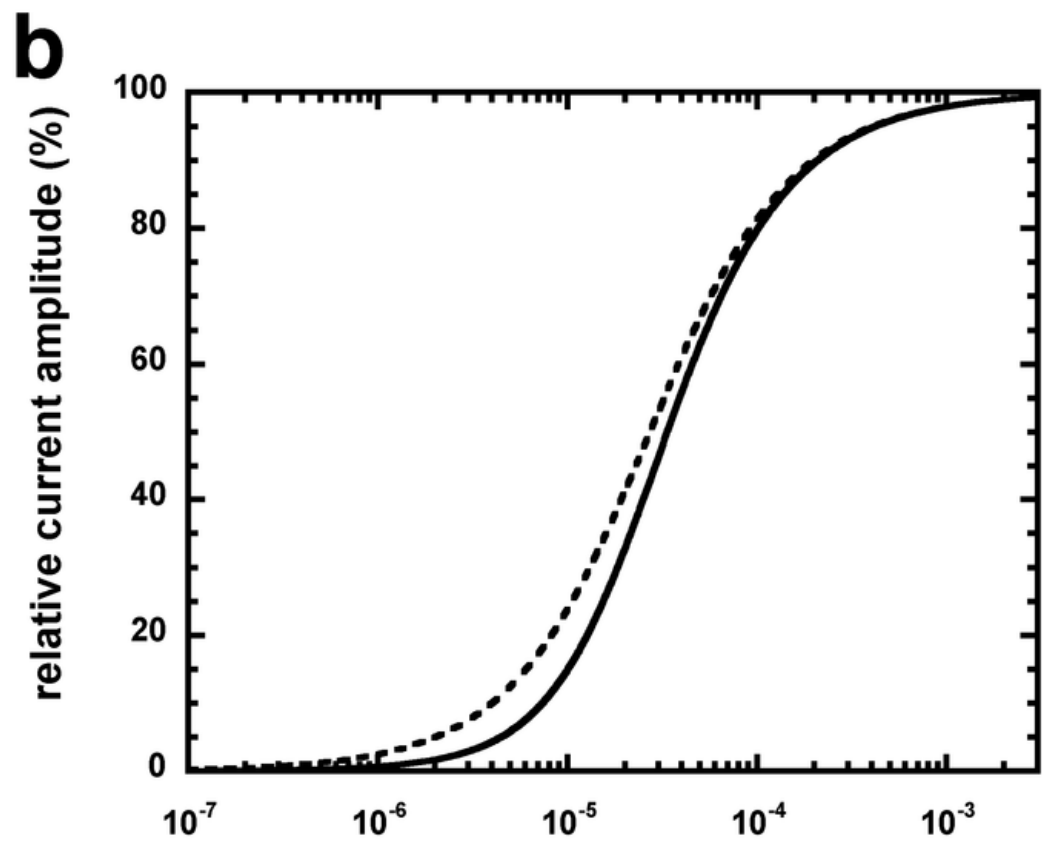

C GABA (M)

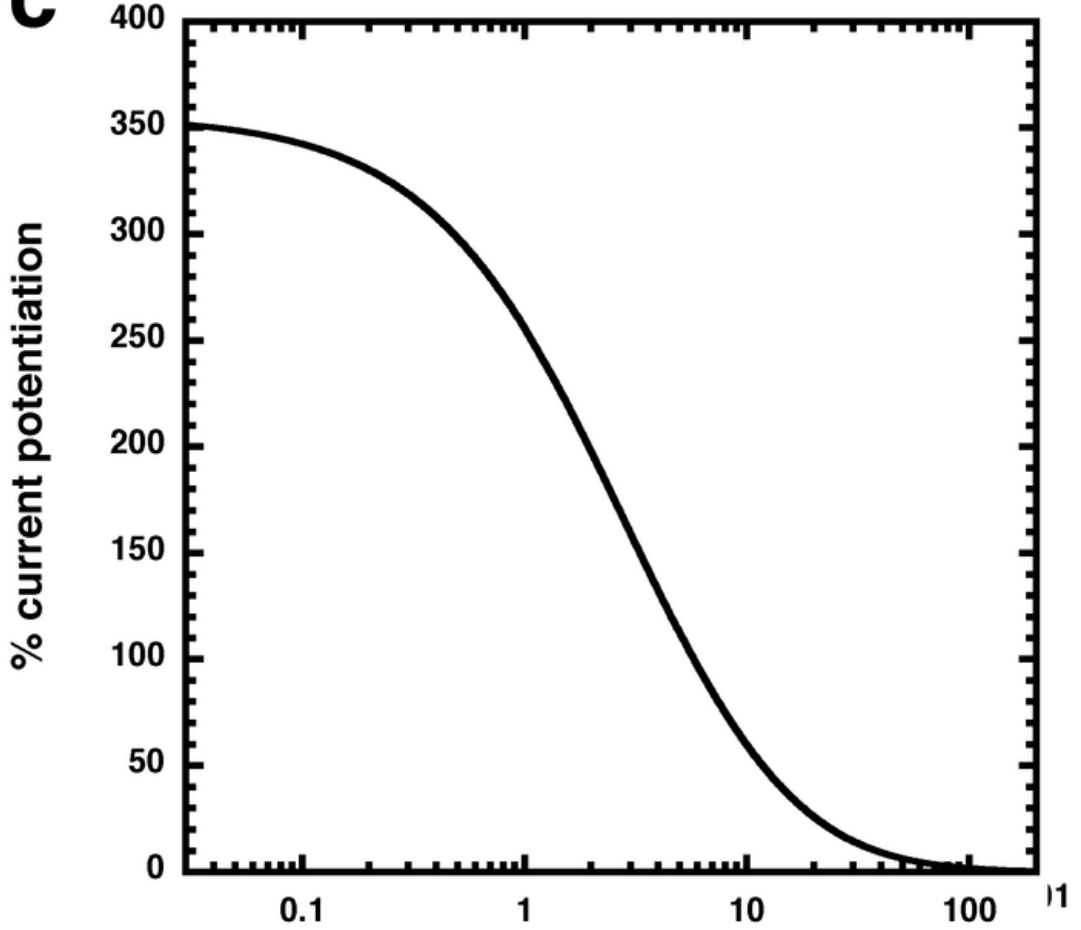

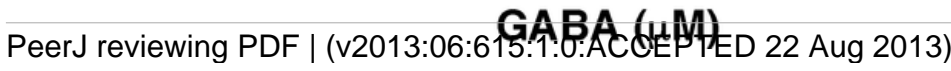




\section{Figure 5}

Concentration inhibition curve of DEA.

Increasing concentrations of DEA were co-applied with $1 \mathrm{M}$ 2-AG (open circles), $3 \mathbb{M} 2-A G$ (open squares), $15 M$ 2-AG (open diamonds), $0.5 M N$ NA-glycine (filled circles), or $3 M N A-$ glycine (filled squares). Data are shown as mean \pm SEM $(n=4)$.

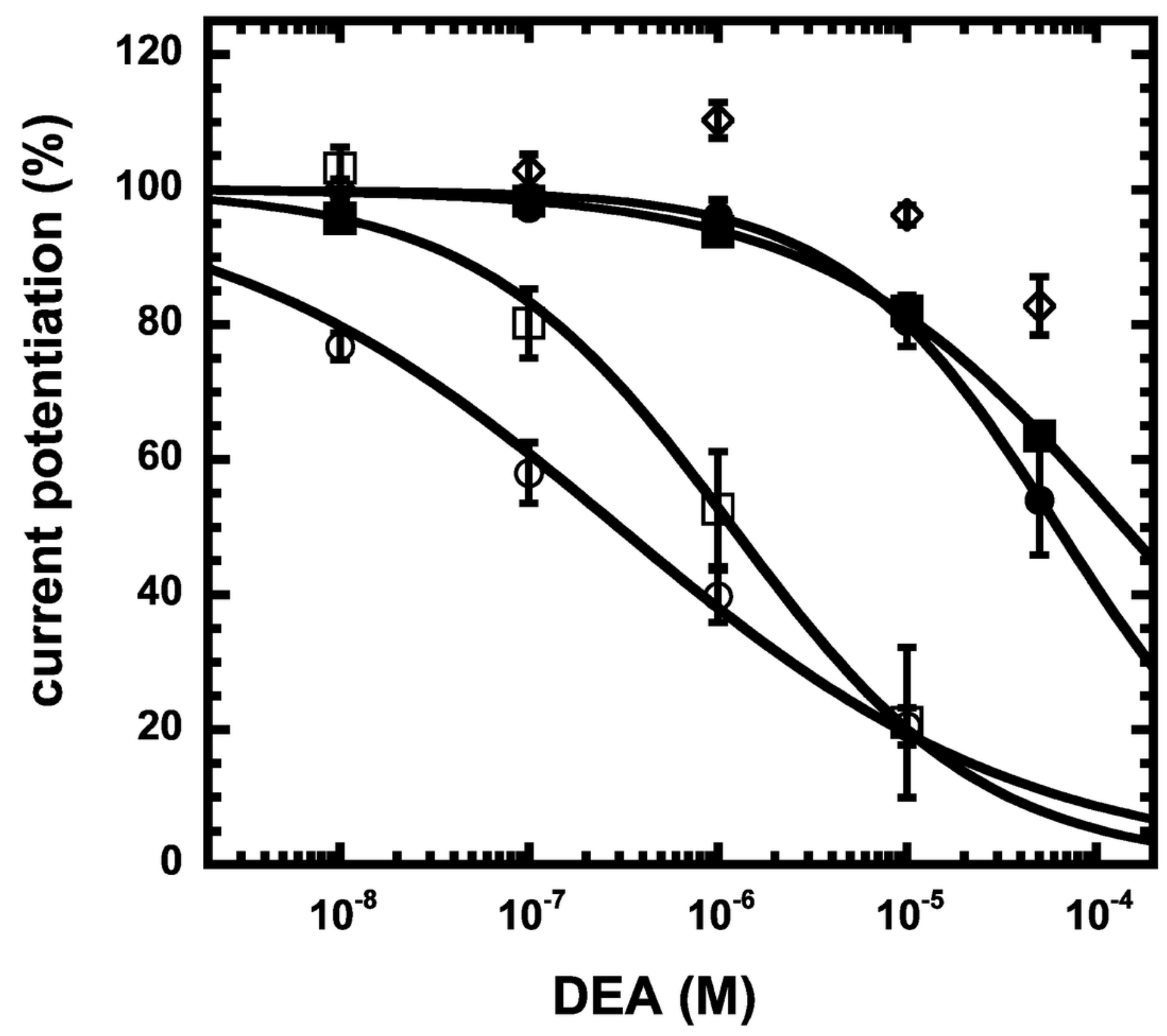




\section{Figure 6}

Effect of subunit combination and co-application with 2-AG

a) Current potentiation by the combined application of $3 \mathrm{M}$ NA-glycine and $3 \mathrm{mM} 2-\mathrm{AG}$ is compared with the individual application of the two substances. b) Current potentiation by 3 M NA-glycine in $\alpha_{1} \beta_{2} \gamma_{2}$ receptors and $\alpha_{1} \beta_{1} \gamma_{2}$ receptors. Potentiation is strongly dependent on the presence of the $\beta_{2}$ subunit.

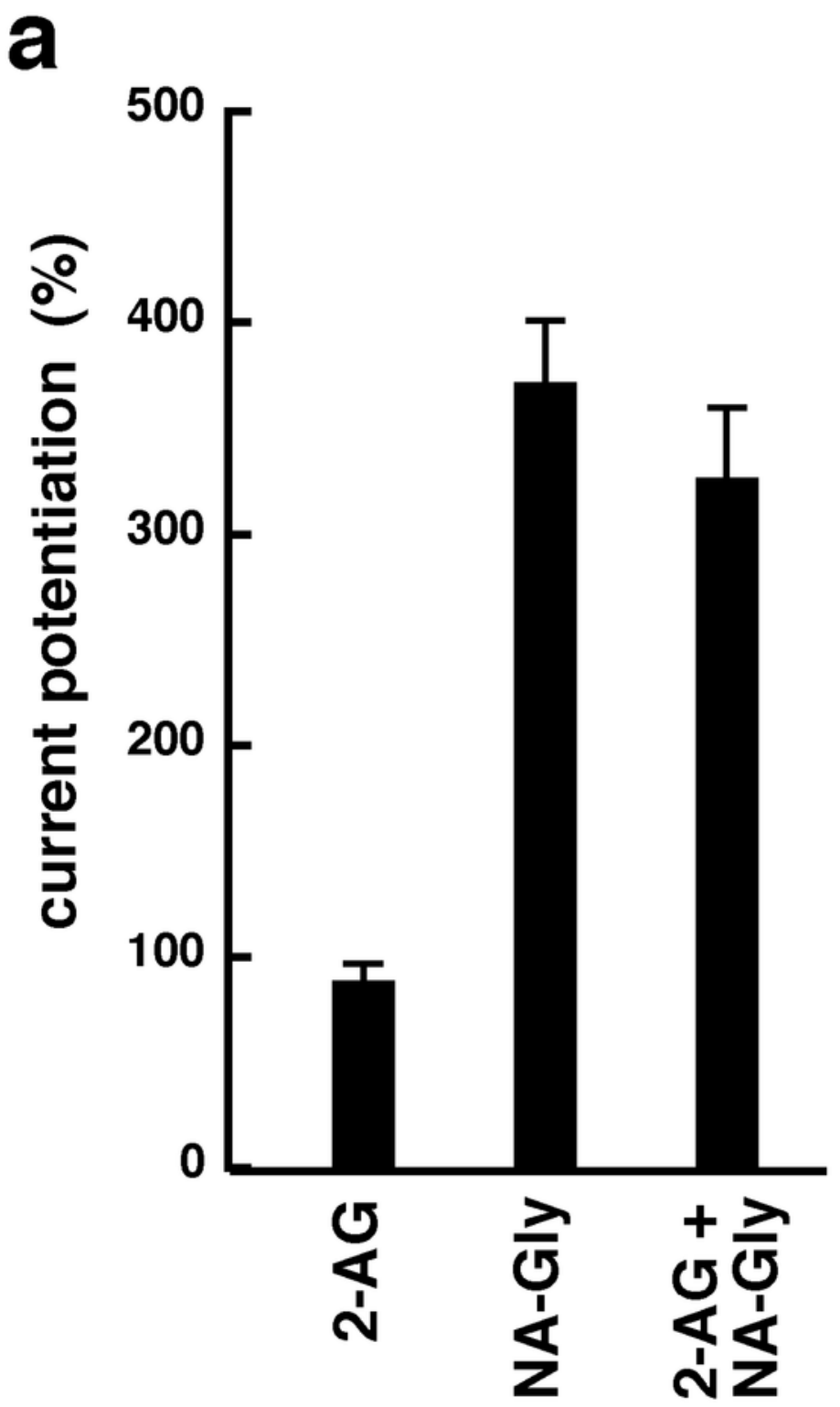

b

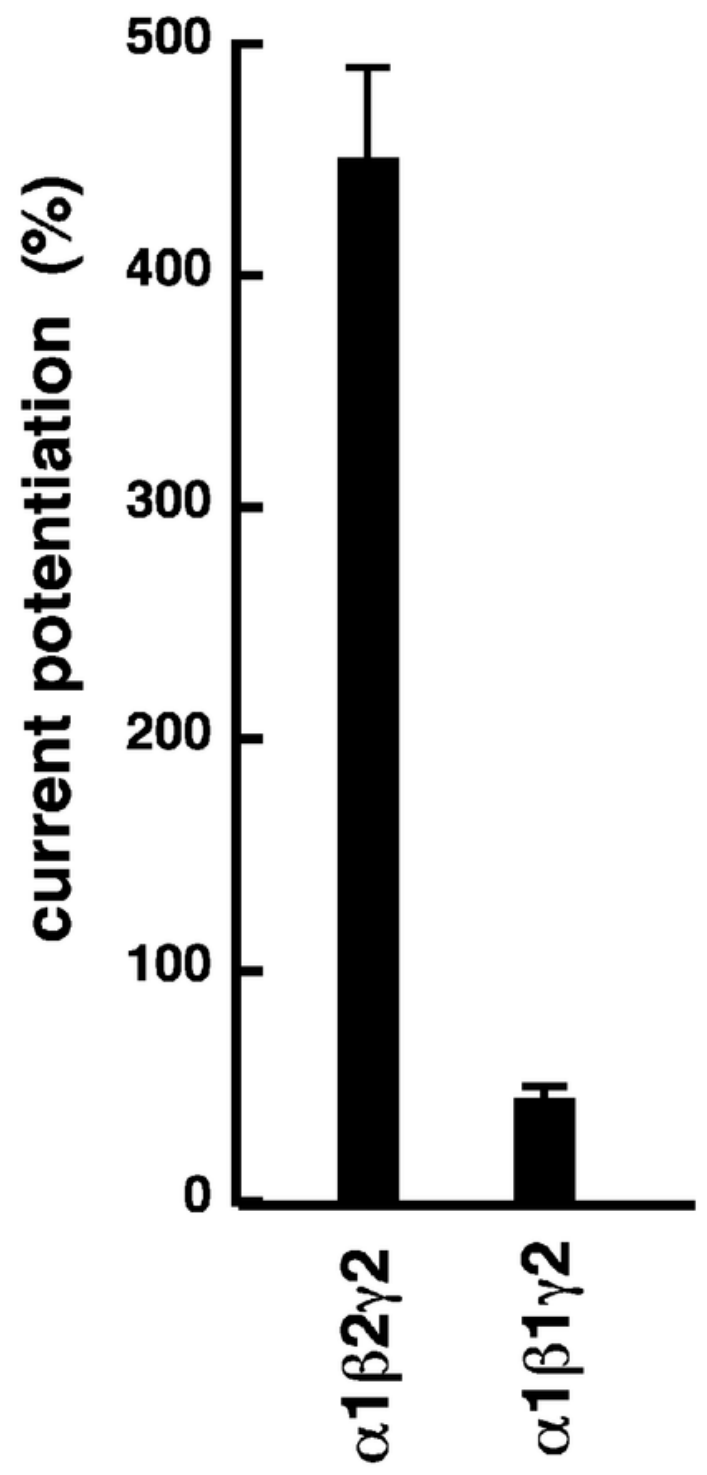




\section{Figure 7}

Concentration-dependent potentiation of currents mediated by concatenated $\mathrm{GABA}_{\mathrm{A}}$ receptors

Concatenated $\alpha_{1}-\beta_{1}-\alpha_{1} / \gamma_{2}-\beta_{1}, \alpha_{1}-\beta_{1}-\alpha_{1} / \gamma_{2}-\beta_{2}, \alpha_{1}-\beta_{2}-\alpha_{1} / \gamma_{2}-\beta_{1}$ or $\alpha_{1}-\beta_{2}-\alpha_{1} / \gamma_{2}-\beta_{2}$

receptors receptors were expressed in Xenopus oocytes and currents were measured at a GABA concentration eliciting $0.5-1.0 \%$ of the maximal current amplitude $\left(\mathrm{EC}_{0.5-1.0}\right)$. Current potentiation by increasing concentrations of NA-glycine was determined. Four such experiments were averaged. Data are shown as mean \pm SD $(n=4)$.

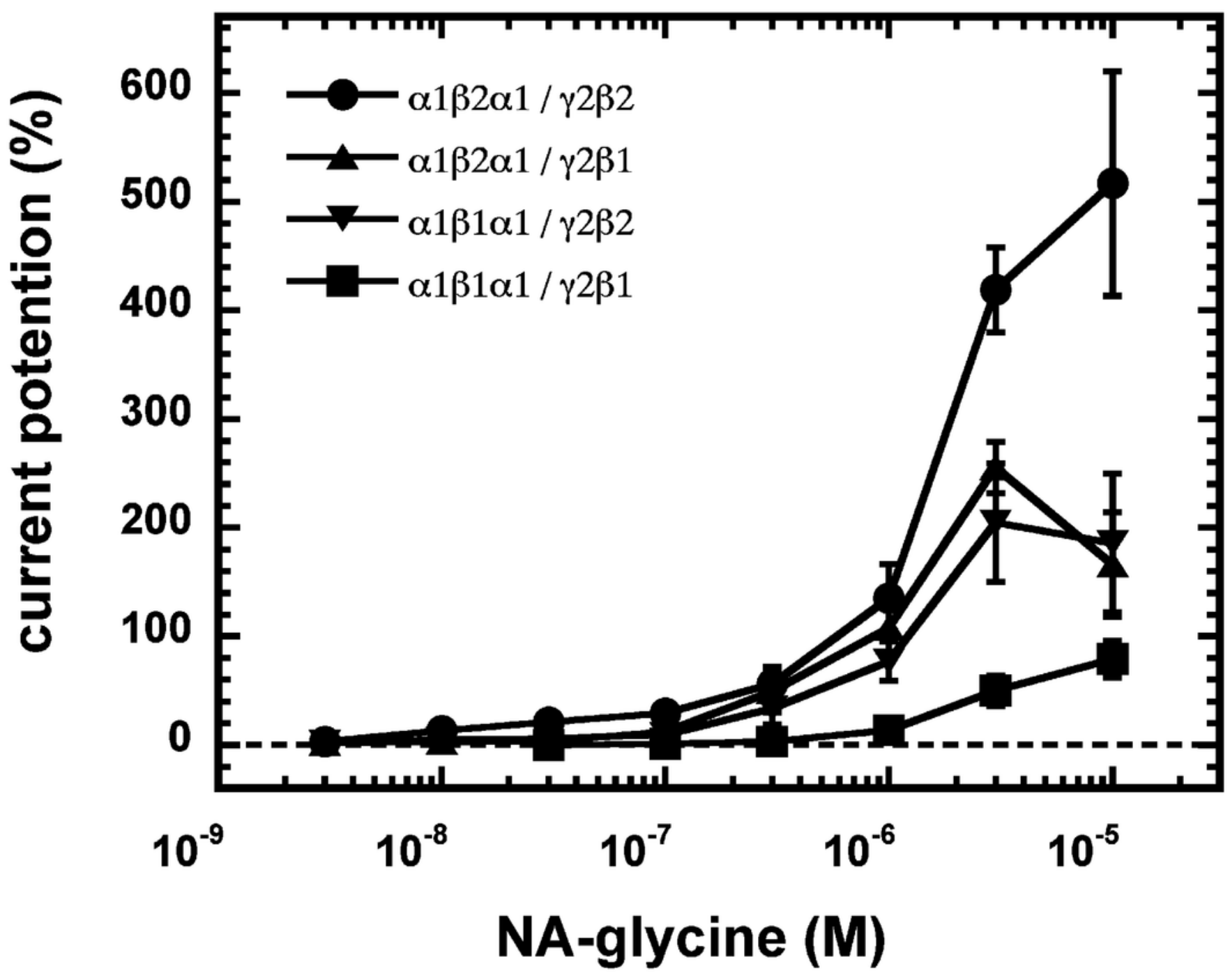




\section{Figure 8}

Effect of point mutations that reduced potentiation by 2-AG on the potentiation of NAglycine.

a) Potentiation by 3 M NA-glycine is compared between wild type receptors and receptors containing the point mutation $\mathrm{S429C}$ in the $\beta_{2}$ subunit. This mutation results at the beginning of the drug application in an about 50\% reduction of potentiation and after $1 \mathrm{~min}$ drug application potentiation is abolished. b) Wild type receptors are compared with mutant receptors. Current potentiation is indicated at the beginning of the drug application (filled bars) and after 1 min drug exposure (open bars). 
a

$\alpha 1 \beta 2 \gamma 2$
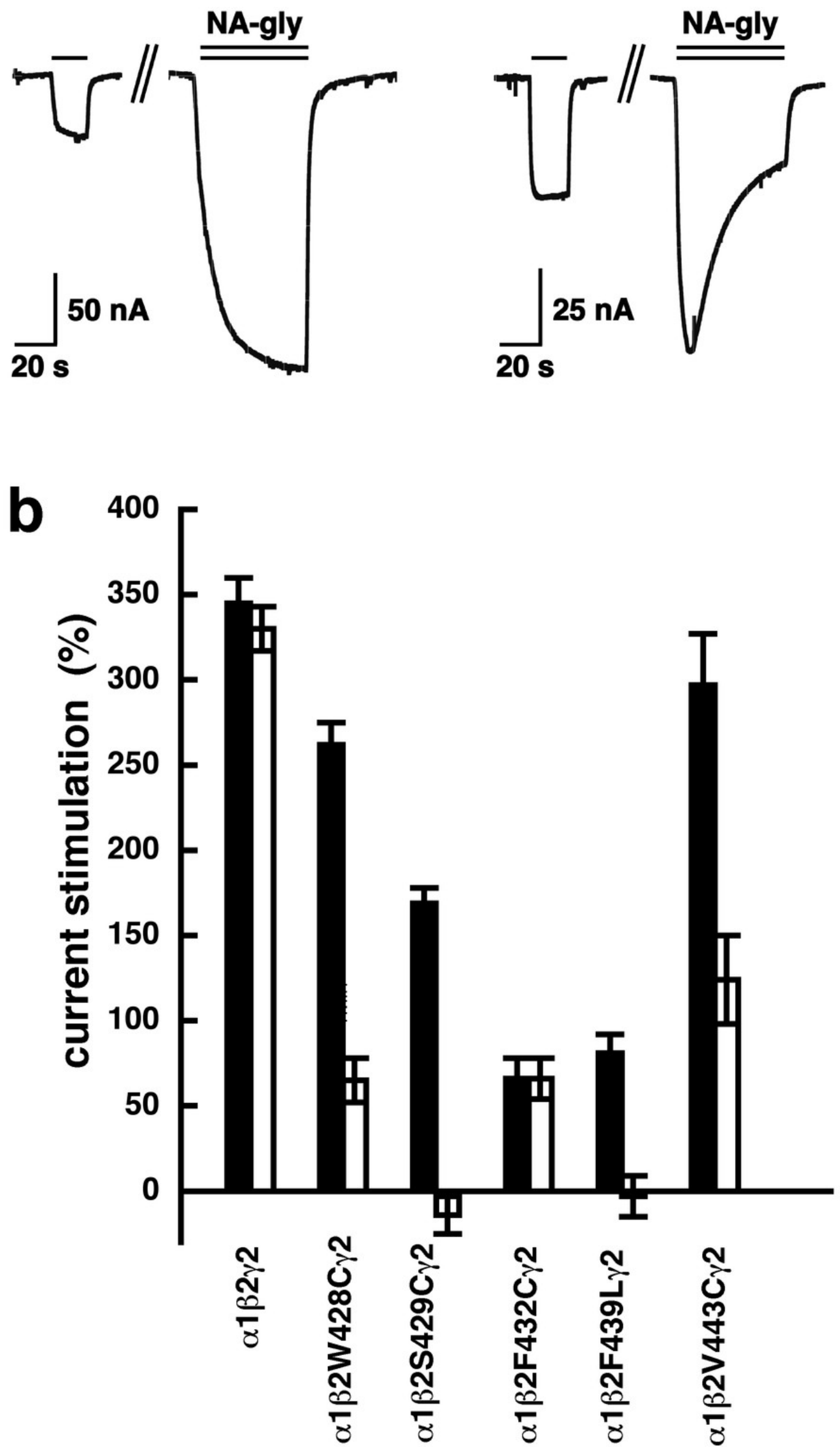


\section{Figure 9}

Time course of the potentiation by NA-glycine

An oocyte expressing $a_{1} \beta_{2} \gamma_{2}$ receptors was sequentially exposed to medium alone, to $1 \mathbb{M}$ GABA, to the same concentration of GABA in combination with 5 M NA-glycine, to 1 microM GABA alone and the to medium. This experiment was repeated two more times with similar results.

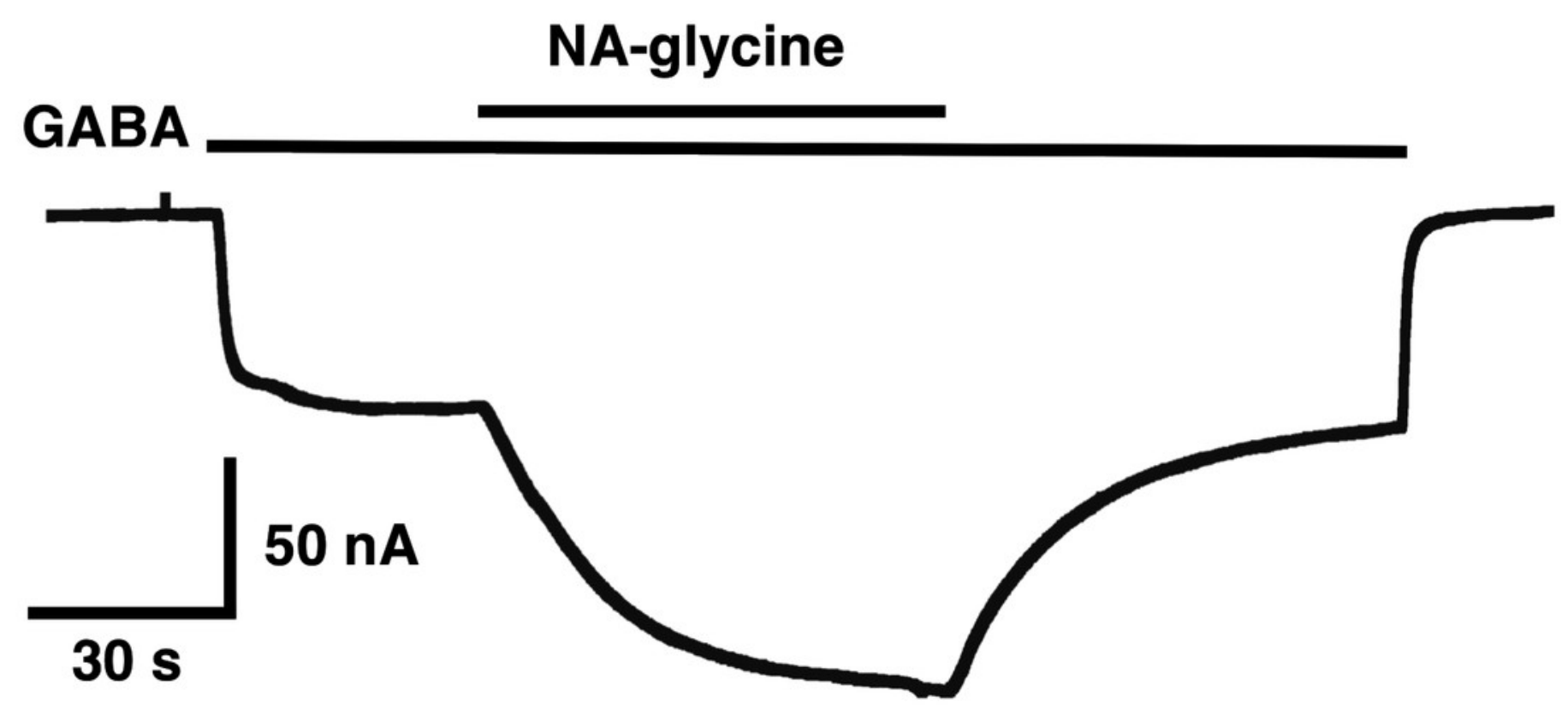

